\title{
Fabrication of polyimide nanotubes and carbon nanotubes containing magnetic iron oxide in confinement
}

\author{
Jyongsik Jang,* Kyung Jin Lee and Younggeun Kim \\ Received (in Cambridge, UK) 16th March 2005, Accepted 27th May 2005 \\ First published as an Advance Article on the web 23rd June 2005 \\ DOI: 10.1039/b503831f
}

Polyimide nanotubes with tunable wall thickness were fabricated by a precursor impregnation method using an AAO template, and carbon nanotubes containing magnetic iron oxide were obtained using ferric chloride-embedded polyimide precursor by a carbonization process.

Nanotubular materials have attracted considerable attention owing to their various applications in the fields of electronics, optics, catalysis, energy storages, and bio-sensors. ${ }^{1}$ Up to date, diverse methods for the preparation of inorganic and organic nanotubes such as titania, silica, and pyrene have been developed. ${ }^{2}$ Polymer nanotubes could also be prepared by several synthetic methods including a soft or hard template-assisted approach, selfassembly, sol-gel methods, and electospinning. ${ }^{3}$ Most research has focused on thermoplastics and conducting polymer.

On the other hand, there is limited information concerning the fabrication of thermoset nanomaterials using mesoporous silica and block copolymer as a template. ${ }^{4}$ Hillmyer et al. and Mijovic groups have reported the synthesis of thermoset nanostructured materials from self-assembled amphiphilic block copolymer/epoxy resin mixture. Among thermoset polymers, aromatic polyimides are important materials because they have excellent mechanical, dielectric and thermal properties. ${ }^{5}$ Recently, electrospinning and drying-jet techniques have been used for the fabrication of polyimide hollow fibers. ${ }^{6}$ However, polyimide nanotubes have not been synthesized yet and this is the first demonstration of a fabricated polyimide tubular structure using a precursor impregnated AAO template method. The hard template method provides not only facile synthesis of the desired material within the cylindrical and spherical porous substrates but also the ability to control the wall thickness of tubular materials. Precise control of the wall thickness can enhance physical and chemical properties such as electrical conductivity, surface area, permeability, and selectivity of the nanotubes. These improved performances could be applied in various research fields, e.g. in chemical and biological sensors, catalysts, separation system, double layer capacitors and hydrogen storage systems. ${ }^{7}$

Carbon nanotubes have been studied for their extensive application fields as well as the fabrication methods. The polymer precursor-mediated method has excellent advantages in the fabrication of tailored carbon nanotubes and for introducing foreign materials that exhibit functional properties such as magnetic, photonic, and biological properties into the carbon

Hyperstructured Organic Materials Research Center and School of Chemical Engineering, College of Engineering, Seoul National University, Shinlimdong 56-1, Seoul, 151-742, Korea.

E-mail: jsjang@plaza.snu.ac.kr; Fax: 822888 7295; Tel: 8228807069 nanotube. ${ }^{8}$ In particular, magnetic carbon nanotubes have been used for magnetic data storage, improved magnetic tapes, and heterogeneous catalysis. ${ }^{9}$ The fabrication of carbon nanotubes with magnetic properties and tunable wall thickness is therefore a challenge. Herein we report on the facile synthesis of polyimide nanotubes using an AAO template and the conversion into carbon nanotubes through the carbonization process.

Scheme 1 illustrates the overall synthetic procedure of fabrication of PI nanotubes and carbon nanotubes containing iron oxide by wetting method. In the synthesis of polyimide nanotubes, poly(pyromellitic dianhydride-co-4,4-oxydianiline) amic acid (PMDA-ODA PAA) was employed as polyimide precursor and was dissolved in $N$-methyl pyrrolidone (NMP). The poly(amic acid) solution was dropped onto the AAO surface (thickness of $60 \mu \mathrm{m}$ and pore diameters of $100 \mathrm{~nm}$ ) and migrated into the AAO pores by capillary force. Subsequently, the solvent was evaporated at $200{ }^{\circ} \mathrm{C}$. Consequently, poly(amic acid) nanotubes could be constructed in the AAO confinement. The polymer impregnated AAO membrane was moved to a furnace, and the poly(amic acid) precursor was cured by heating to $300{ }^{\circ} \mathrm{C}$ at a heating rate of $3{ }^{\circ} \mathrm{C} \min ^{-1}$ under nitrogen atmosphere. After the imidization, the AAO template was dissolved in hydrochloric acid (3 M). Excess water was added to dilute the solution, and the polyimide nanotubes were precipitated by ultracentrifugation (4000 rpm, $10 \mathrm{~min}$ ). The polyimide nanotubes were placed in a quartz tube,
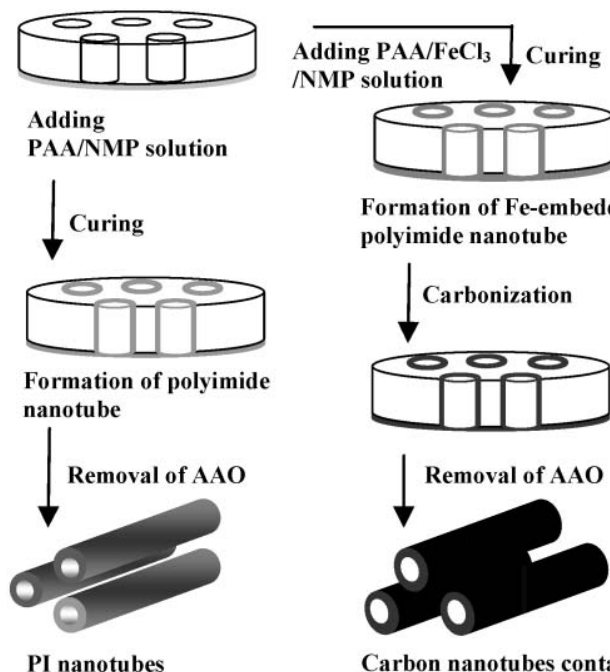

Formation of Fe-embedded polyimide nanotube

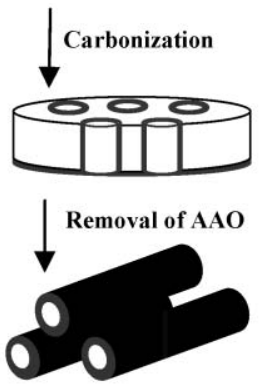

Carbon nanotubes containing magnetic iron oxide

Scheme 1 Schematic diagram of fabrication of PI nanotubes and carbon nanotubes containing iron oxide by wetting method using an AAO template. 
and heated up to $800{ }^{\circ} \mathrm{C}$ at a heating rate of $3{ }^{\circ} \mathrm{C} \mathrm{min}{ }^{-1}$ under $\mathrm{N}_{2}$ condition. After carbonization, the quartz tube was allowed to cool to room temperature. Ferric chloride was introduced into poly(amic acid)/NMP solution in order to fabricate carbon nanotubes containing magnetic properties. In this case, ironimpregnated poly(amic acid) nanotubes were formed in the channels of AAO and iron-embedded polyimide nanotubes were produced by subsequent imidization process. Carbon nanotubes containing magnetic iron oxide were successfully fabricated via the conversion of $\mathrm{Fe}$ element into magnetic iron oxide during the carbonization process.

Fig. 1 represents the FT-IR spectra of poly(amic acid) and polyimide nanotubes synthesized in the AAO channels. In Fig. 1a, there are some characteristic peaks of poly(amic acid) precursor. The band at $1660 \mathrm{~cm}^{-1}$ is attributed to $\mathrm{C}=\mathrm{O}$ stretching vibration in CONH and the peak at $1550 \mathrm{~cm}^{-1}$ is associated with $\mathrm{C}-\mathrm{NH}$ stretching vibration. In addition, the broad bands at around $3200 \mathrm{~cm}^{-1}$ are due to $\mathrm{O}-\mathrm{H}$ stretching vibration and $\mathrm{N}-\mathrm{H}$ deformation vibration. After the imidization process, new bands corresponding to polyimide appeared: $\mathrm{C}=\mathrm{O}$ symmetric stretching vibration at $1770 \mathrm{~cm}^{-1}$ and $\mathrm{C}=\mathrm{O}$ asymmetric stretching vibration at $1725 \mathrm{~cm}^{-1}, \mathrm{C}-\mathrm{N}$ stretching vibration at $1376 \mathrm{~cm}^{-1}$, and at $722 \mathrm{~cm}^{-1}$ for $\mathrm{C}=\mathrm{O}$ bending. Judging from these spectra, it was evident that polyimide was successfully generated through curing poly(amic acid). ${ }^{6}$

Fig. 2a shows a SEM image of polyimide nanotubes synthesized in AAO channels. The average diameter and length of polyimide nanotubes are $100 \mathrm{~nm}$ and $60 \mu \mathrm{m}$ and these values have good agreement with those of th AAO template. Fig. 2b, c, and d illustrate the wall thickness variation of polyimide nanotubes. The wall thickness of polyimide nanotubes could be easily controlled by changing the precursor concentration. The diluted polyamic acid solution makes it possible to construct the tubular structure because the diluted solution exhibits low surface energy. ${ }^{10}$ When the solution concentration of poly(amic acid) was $0.02 \mathrm{wt} \%$, PI nanotubes were fabricated with wall thickness $20 \pm 5 \mathrm{~nm}$ (Fig. 2b). Control of wall thickness was attempted by changing the concentration of poly(amic acid) precursor. At a precursor concentration of $0.05 \mathrm{wt} \%$, the wall thickness of PI nanotube was $33 \pm 5 \mathrm{~nm}$ and increased up to $40 \pm 5 \mathrm{~nm}$ at $0.1 \mathrm{wt} \%$ of

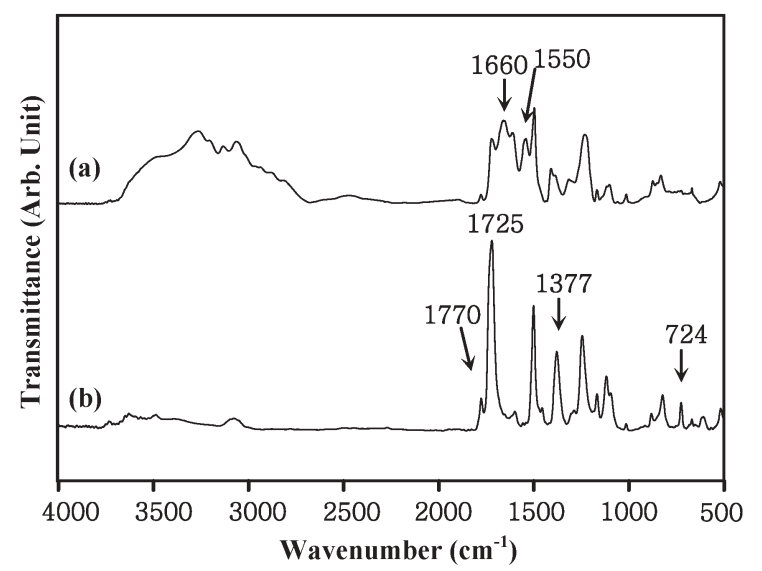

Fig. 1 FT-IR spectra of (a) PMDA-ODA poly(amic acid) and (b) polyimide nanotubes in the channel of AAO membrane.
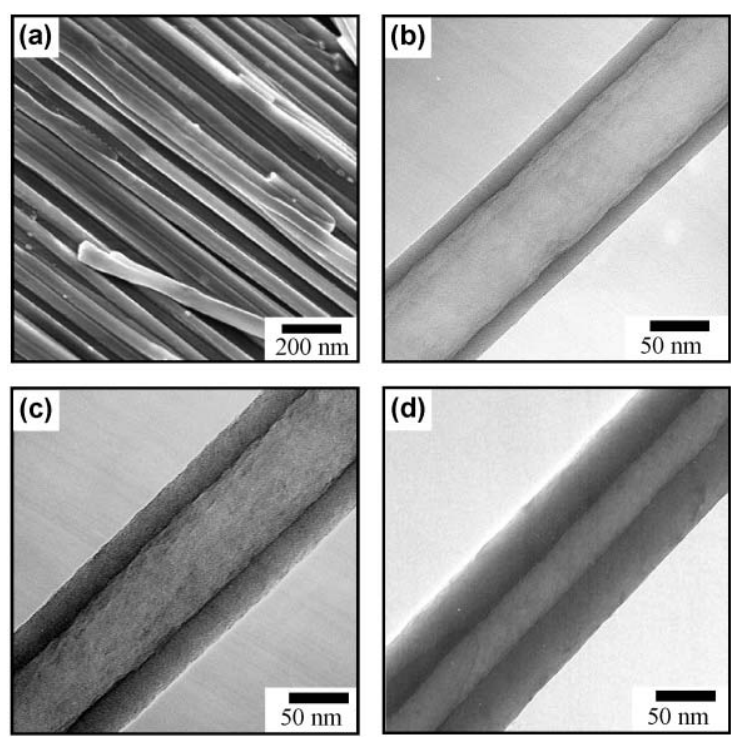

Fig. 2 SEM image (a) of polyimide nanotubes prepared using AAO membranes and TEM images representing the wall thickness variation by controlling the concentration of polymer precursor solution: (b) $0.02 \mathrm{wt} \%$, (c) $0.05 \mathrm{wt} \%$, and (d) $0.1 \mathrm{wt} \%$.

poly(amic acid). However, polyimide nanofibers can be formed at a high concentration ( $1 \mathrm{wt} \%$ ) of PAA/NMP solution.

Fig. 3a, b, and c display the TEM images of carbon nanotubes originated from polyimide nanotubes using AAO membrane with pore size of $100 \mathrm{~nm}$. The diameter and shell thickness of carbon nanotubes reduced by approximately $15 \mathrm{~nm}$ and $5 \mathrm{~nm}$ respectively compared with those of polyimide nanotubes. It is known that the size reduction of the carbon nanotubes is attributed to the formation of more compact structures during the carbonization process. $^{11}$

Fig. 3d represents the Raman spectrum of polyimide nanotube carbonized at $800{ }^{\circ} \mathrm{C}$. The peak at $1590 \mathrm{~cm}^{-1}$ (G band) is
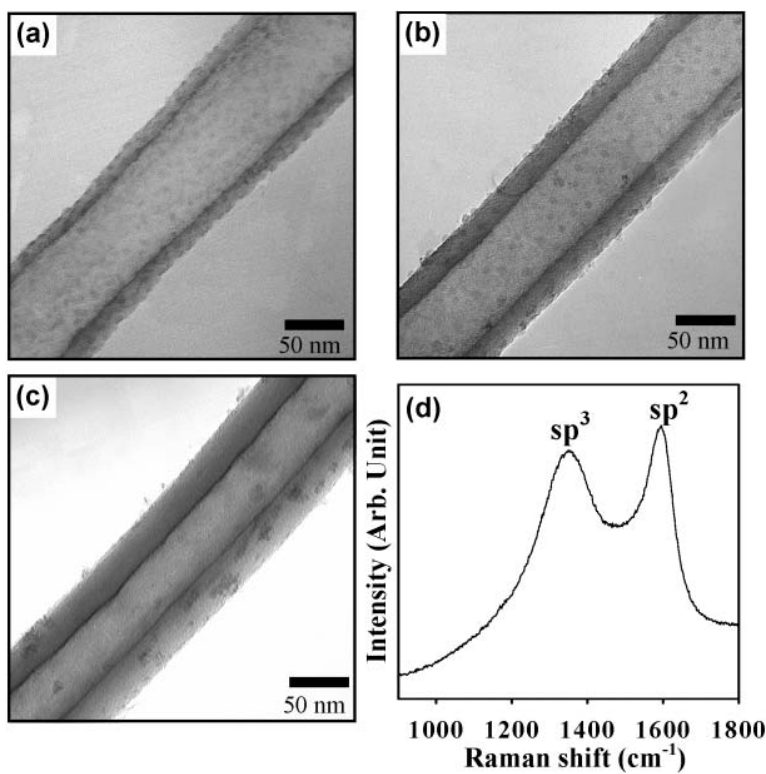

Fig. 3 (a), (b), (c) TEM images and (d) Raman spectrum of the carbon nanotubes with tunable wall thickness originated from polyimide. 

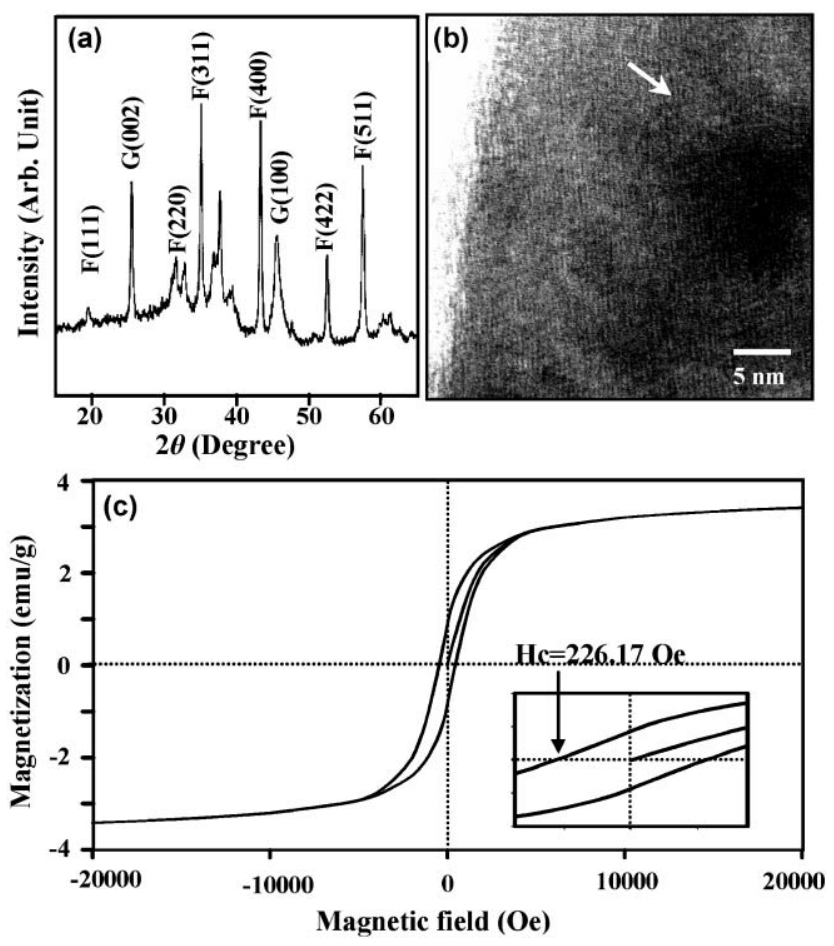

Fig. 4 a) X-ray diffraction pattern, b) HRTEM image and c) hysteresis loop of $\mathrm{Fe}_{2} \mathrm{O}_{3}$ embedded carbon nanotubes generated from polyimide nanotubes. The inset graph is hysteresis loop between -350 and 350 Oe expanded.

attributed to the $\mathrm{E}_{2 \mathrm{~g}}$ vibration of graphitic carbon with an $\mathrm{sp}^{2}$ electronic configuration. The band at $1350 \mathrm{~cm}^{-1}$ ( $\mathrm{D}$ band) is due to the $\mathrm{A}_{1 \mathrm{~g}}$ mode ascribed to diamond-like carbon with $\mathrm{sp}^{3}$ configuration. ${ }^{12}$ The relative intensity $\left(I_{\mathrm{D}} / I_{\mathrm{G}}\right)$ of carbonized polyimide nanotubes is 0.43 . Compared with carbonized polyacrylonitrile at the same carbonization temperature, the Raman spectrum of the carbonized polyimide nanotube exhibits an increased intensity value of $I_{\mathrm{D}} / I_{\mathrm{G}}$. On the other hand, polyimide based carbon nanotubes have slightly different structures compared to CNTs prepared by the arc-evaporation method. The carbon nanotubes have a semicrystalline carbon structure with some lattice edges or plane defects. ${ }^{13}$ In general, CNTs prepared by carbonizing polymer precursor have inevitably amorphous region at low carbonization temperature. However, the degree of graphitization could be enhanced if the precursor has lots of aromatic composition ${ }^{14}$. Therefore, the graphitic structure of carbonized polyimide nanotubes is well developed at relatively low carbonization temperature due to the aromatic composition of polyimide, as shown in Raman spectrum or HRTEM images.

Fig. 4a reveals the XRD pattern of carbon nanotubes containing magnetic iron oxide. The two characteristic peaks were observed, as the peaks of graphene carbon and $\gamma-\mathrm{Fe}_{2} \mathrm{O}_{3}$ are clearly marked "G" and "F", respectively. ${ }^{8}$ The high resolution TEM (HRTEM) image (Fig. 4b) confirmed that the carbon nanotubes consisted of the partially graphitic layers and involved iron oxide compound (arrow). The magnetic properties of carbon nanotubes containing magnetic iron oxide produced by carbonization of iron-embedded polyimide nanotubes are measured using a superconducting interference device (SQUID) magnetometer. The hysteresis loop of magnetization is displayed in Fig. 4c. The magnetization hysteresis loop was measured in fields between $\pm 20 \mathrm{kOe}$ at $300 \mathrm{~K}$. The saturation of the magnetization was observed above $\sim 15 \mathrm{kOe}$, and magnetic coercive field $\left(H_{\mathrm{c}}\right)$ was 226.17 Oe. This $H_{\mathrm{c}}$ value is considerably higher than that of bulk iron $\left(H_{\mathrm{c}} \sim 1 \mathrm{Oe}\right)$. The remnant magnetization of the $\gamma-\mathrm{Fe}_{2} \mathrm{O}_{3}$ impregnated carbon nanotubes was estimated about $0.86 \mathrm{emu} \mathrm{g}^{-1}$.

In summary, polyimide nanotubes with tunable wall thicknesses have been fabricated successfully by wetting the polymer precursor solution in the channels of the AAO template followed by a curing process. Graphitic carbon nanotubes and carbon nanotubes containing magnetic iron oxide could be produced through carbonization of polyimide nanotubes.

This work was supported by Korea Science and Engineering Foundation through the Hyperstructured Organic Materials Research Center.

\section{Notes and references}

1 J. Kong, N. Franklin, C. Zhou, M. Chapline, S. Peng, K. Cho and H. Dai, Science, 2000, 287, 622; K. Bradley, J. Cabriel and G. Gruner, Nano Lett., 2003, 3, 1353.

2 T. Kasuga, M. Hiramatsu, A. Hoson, T. Sekino and K. Niihara, $A d v$. Mater., 1999, 11, 1307; H. Nakamur and Y. Matsui, J. Am. Chem. Soc., 1995, 117, 2651.

3 J. Jang and J. H. Oh, Chem. Commun., 2004, 882; W. J. Blau and A. J. Fleming, Science, 2004, 304, 1457; J. Jang and H. Yoon, Chem. Commun., 2003, 720; M. Steinhart, J. H. Wendorff, A. Greiner, R. B. Wehrspohn, K. Nielsch, J. Schilling, J. Choi and U. Gosele, Science, 2002, 296, 1997; X. Wang, A. Winnik and I. Manners, Angew. Chem. Int. Ed., 2004, 43, 3703.

4 M. A. Hillmyer, P. M. Lipic, D. A. Hajduk, K. Almadal and F. S. Bates, J. Am. Chem. Soc., 1997, 119, 2749; P. M. Lipic, F. S. Bates and M. A. Hillmyer, J. Am. Chem. Soc., 1998, 120, 8963; J. Mijovic, M. Shen and J. W. Sy, Macromolecules, 2000, 33, 5235; H. Kosonen, J. Ruokolainee, P. Nyholm and O. Ikkala, Macromolecules, 2001, 34, 3046; M. Groenewolt, A. Thomas and M. Antonietti, Macromolecules, 2004, 37, 4360

5 J. A. Kreuz and J. R. Edman, Adv. Mater., 1998, 10, 1229; M. L. Bruening and D. M. Sullivan, Chem. Eur. J., 2002, 8, 3833; D. M. Sullivan and M. L. Bruening, J. Am. Chem. Soc., 2001, 123, 11805.

6 C. Nah, S. H. Han, M. H. Lee, J. S. Kim and D. S. Lee, Polym. Int., 2003, 52, 429.

7 M. Wirtz, M. Parker, Y. Kobayashi and C. R. Martin, Chem. Eur. J, 2002, 8, 3573; J. -S. Lee, S. H. Joo and R. Ryoo, J. Am. Chem. Soc., 2002, 124, 1156; H. Shin, D.-K. Jeong, J. Lee, M. M. Sung and J. Kim, Adv. Mater., 2004, 16, 1197.

8 J. Jang and H. Yoon, Adv. Mater., 2003, 15, 2088; G. T. Visscher, D. C. Nesting, J. V. Badding and P. A. Bianconi, Science, 1993, 260, 1496; J. N. Barsema, N. F. A. van der Vegt, G. H. Koops and M. Wessling, Adv. Funct. Mater., 2005, 15, 69.

9 J. Bao, C. Tie, Z. Xu, Q. Zhou, D. Shen and Q. Ma, Adv. Mater., 2001, 13, 1631; C. P. Huu, N. Keller, C. Estournes, G. Ehret, J. M. Greneche and M. J. Ledoux, Phys. Chem. Chem. Phys., 2003, 5, 3716.

10 M. Steinhart, R. B. Wehrspohn, U. Gosele and J. H. Wendorff, Angew. Chem. Int. Ed., 2004, 43, 1334.

11 K. Kim and J. -I. Jin, Nano Lett., 2001, 1, 631.

12 F. Tuinstra and J. L. Koenig, J. Chem. Phys., 1970, 53, 1126.

13 M. S. Dresselhaus, P. C. Eklund, G. Dresselhaus and M. J. Pelletier, Analytical Application of Raman Spectroscopy, Blackwell Science, Oxford, 1st edition., 1999, ch. 9.

14 C. H. Kim, D. K. Lee and T. J. Pinnavaia, Langmuir, 2004, 20, 5157; E. Fitzer and D. J. Muller, Carbon, 1975, 13, 63; E. Fitzer and D. J. Muller, Carbon, 1975, 13, 63. 